\title{
Conhecimento de estudantes do curso Técnico em Enfermagem sobre suporte básico
}

\section{de vida}

\author{
Knowledge of students in the Technical Nursing course on basic life support \\ Conocimientos de los estudiantes del curso Técnico de Enfermería sobre soporte vital básico
}

Recebido: 22/12/2020 | Revisado: 29/12/2020 | Aceito: 31/12/2020 | Publicado: 04/01/2021

Flávia Helena Pereira

ORCID: https://orcid.org/0000-0001-9331-7020 Instituto Federal de Educação, Ciência e Tecnologia do Sul de Minas Gerais, Brasil E-mail: flavia.pereira@ifsuldeminas.edu.br

Danilo Donizetti Trevian

ORCID: https://orcid.org/0000-0002-6998-9166 Universidade Federal de São João del Rei, Divinópolis, Brasil

E-mail: ddtrevisan@gmail.com

Elizabeth Miranda Vitor da Silva

ORCID: https://orcid.org/0000-0002-6049-0131 Instituto Federal de Educação, Ciência e Tecnologia do Sul de Minas Gerais, Brasil

E-mail: betvit2010@hotmail.com

Neila Cristina Ribeiro Souza

ORCID: https://orcid.org/0000-0002-1765-4962 Instituto Federal de Educação, Ciência e Tecnologia do Sul de Minas Gerais, Brasil

E-mail: neilaribsouza@gmail.com

Rodrigo Gomes de Morais

ORCID: https://orcid.org/0000-0003-2174-0967 Instituto Federal de Educação, Ciência e Tecnologia do Sul de Minas Gerais, Brasil

E-mail:rodrigoenfmorais@hotmail.com

Juliano de Souza Caliari

ORCID: https://orcid.org/0000-0002-3021-1138 Instituto Federal de Educação, Ciência e Tecnologia do Sul de Minas Gerais, Brasil

E-mail: juliano.caliari@ifsuldeminas.edu.br

Ana Paula Alonso Reis Mairink

ORCID: https://orcid.org/0000-0001-9812-9344 Instituto Federal de Educação, Ciência e Tecnologia do Sul de Minas Gerais, Brasil

E-mail:ana.reis@muz.ifsuldeminas.edu.br

Ariane Ranzani Rigotti

ORCID: https://orcid.org/0000-0002-7440-7044

Universidade de São Paulo, Brasil

E-mail: arianerrigotti@gmail.com

Maria das Graças de Souza Carvalho

ORCID: https://orcid.org/0000-0001-8726-6327

Universidade José do Rosário Vellano, Brasil

E-mail:mariah_roots@ @otmail.com

José Antonio Dias Garcia

ORCID: https://orcid.org/0000-0002-4024-3045

Instituto Federal de Educação, Ciência e Tecnologia do Sul de Minas Gerais, Brasil

Universidade José do Rosário Vellano, Brasil

E-mail: jadiasgarcia@gmail.com

Rafael Fernando Mendes Barbosa

ORCID: https://orcid.org/0000-0003-2063-5145

Universidade do Estado de Minas Gerais, Brasil

E-mail:rafaelfmb16@hotmail.com

\section{Resumo}

Introdução: O conhecimento sobre Suporte Básico de Vida (SBV) pode salvar vidas. Objetivo: Avaliar o conhecimento de estudantes do curso técnico em enfermagem antes e após treinamento teórico sobre Suporte Básico de Vida (SBV) em adultos. Materiais e Métodos: Estudo quase-experimental realizado com 74 estudantes do curso técnico em enfermagem de uma instituição de ensino do sul de Minas Gerais. A mensuração das variáveis sociodemográficas e do conhecimento sobre o SBV foi realizada a partir de questionário validado previamente. Por meio do software IBM ® SPSS 23.0, os testes de Mcnenar e Wilcoxon foram utilizados para comparar a proporção de acertos e a mediana do nível de conhecimento. Resultados: A mediana do conhecimento dos estudantes após o treinamento foi significantemente maior que no pré-teste $(\mathrm{p}<0,001)$. Entretanto, as questões que envolviam o acionamento do serviço de urgência/emergência e a realização da ressuscitação cardiopulmonar foram as únicas que apresentaram aumento 
significativo do número de acertos. Discussão: O treinamento teórico foi capaz de incrementar o conhecimento de estudantes do curso técnico em enfermagem, entretanto, apenas nas questões que envolviam os elos iniciais da cadeia de sobrevivência pode-se observar um aumento significativo. Conclusão: o treinamento teórico colaborou para a apreensão de conteúdo, melhorando a capacidade cognitiva dos participantes.

Palavras-chave: Parada cardíaca; Reanimação cardiopulmonar; Educação; Estudantes; Técnicos de enfermagem.

\begin{abstract}
Introduction: Knowledge about Basic Life Support (BLS) can save lives. Objective: To evaluate the knowledge of students in the technical course in nursing before and after theoretical training on BLS in adults. Materials and Methods: Quasi-experimental study carried out with 74 students of the technical nursing course at an educational institution in Minas Gerais. The measurement of sociodemographic variables and knowledge about BLS was carried out using a previously validated questionnaire. Using the IBM ® SPSS 23.0 software, the Mcnenar and Wilcoxon tests were used to compare the proportion of correct answers and the median level of knowledge. Results: The median knowledge of students after training was significantly higher than in the pre-test $(p<0.001)$. However, the issues that involved triggering the urgency / emergency service and performing cardiopulmonary resuscitation were the only ones that showed a significant increase in the number of correct answers. Discussion: Theoretical training was able to increase the knowledge of students of the technical course in nursing, however, only in the questions that involved the initial links of the survival chain can a significant increase be observed. Conclusion: the theoretical training contributed to the apprehension of content, improving the cognitive capacity of the participants.
\end{abstract}

Keywords: Heart arrest; Cardiopulmonary resuscitation; Education; Students; Licensed practical nurses.

\title{
Resumen
}

Introducción: El conocimiento sobre soporte vital básico (BLS) puede salvar vidas. Objetivo: Evaluar los conocimientos de los estudiantes del curso técnico en enfermería antes y después de la formación teórica sobre SVB en adultos. Materiales y métodos: estudio cuasiexperimental realizado con 74 estudiantes del curso técnico de enfermería de una institución educativa de Minas Gerais. La medición de variables sociodemográficas y conocimientos sobre SVB se realizó mediante un cuestionario previamente validado. Con el software IBM® SPSS 23.0, se utilizaron las pruebas de Mcnenar y Wilcoxon para comparar la proporción de respuestas correctas y la mediana del nivel de conocimiento. Resultados: La mediana de conocimientos de los estudiantes después de la formación fue significativamente mayor que en la prueba previa ( $\mathrm{p}<0,001)$. Sin embargo, las cuestiones que involucraron la activación del servicio de urgencia / emergencia y la realización de reanimación cardiopulmonar fueron las únicas que mostraron un aumento significativo en el número de respuestas correctas. Discusión: La formación teórica logró incrementar los conocimientos de los estudiantes del curso técnico en enfermería, sin embargo, solo en las preguntas que involucraron los eslabones iniciales de la cadena de supervivencia se puede observar un incremento significativo. Conclusión: la formación teórica contribuyó a la aprehensión de contenidos, mejorando la capacidad cognitiva de los participantes.

Palabras clave: Paro cardíaco; Reanimación cardiopulmonar; Educación; Estudiantes; Enfermeros no diplomados.

\section{Introdução}

O aumento das doenças cardiovasculares (DCV) representa um grave problema de saúde pública em todo o mundo, em especial para os países de baixa e média renda, sendo um importante desafio para a rede de assistência em saúde atual (Gabriel \& Aluko, 2019). Em 2016, estima-se que mundialmente tenha ocorrido mais de 17,9 milhões de óbitos; aproximadamente um terço destes números foi ocasionado por DCV que, na maioria das vezes, evoluiu em parada cardiorrespiratória (PCR) (OMS, 2017).

No Brasil, dados sobre a incidência de PCR ainda são incipientes e escassos. Entre as PCR que ocorrem em ambiente extra-hospitalar, mais de $80 \%$ são acarretadas por Fibrilação Ventricular (FV) e Taquicardia Ventricular (TV). Na presença de uma PCR, caso o suporte básico de vida (SBV) seja corretamente realizado por pessoas leigas treinadas, a partir da identificação de sinais e sintomas de PCR, comunicação do serviço de saúde e início precoce de compressões torácicas e desfibrilação (em até 3 a 5 minutos do início da PCR), as taxas de sobrevida podem chegar de 50 a 70\% (Bernoche et al., 2019; AHA, 2020).

Entretanto, dados das Diretrizes de 2020 da AHA para ressuscitação cardiopulmonar (RCP) e atendimento cardiovascular de emergência (ACE), descrevem que menos de 40\% dos adultos recebem RCP iniciada por leigos e menos de 12\% atendimento com um Desfibrilador Externo Automático (DEA) antes da chegada do serviço de urgência/emergência. Esses achados enfatizam a importância do treinamento de leigos para o SBV, o qual pode ocorrer em diversos espaços e abranger pessoas que não integram a rede de assistência, como por exemplo, estudantes do ensino médio, técnico ou superior (AHA, 
2020).

Em relação aos estudantes de enfermagem, alguns estudos (Silva et al., 2015; Matos, Souza \& Alves, 2016; Silva et al., 2020) avaliaram o conhecimento sobre os protocolos do Suporte Básico de Vida (SBV) tanto teórico quanto prático e identificaram que o conhecimento sobre esta temática, ou seja, que envolvem o cumprimento dos elos da cadeia de sobrevivência (acionamento do serviço de emergência, realização de RCP com alta qualidade, desfibrilação precoce e cuidados pós-RCP) foi insuficiente. $\mathrm{O}$ desconhecimento em parte pode estar relacionado a uma lacuna durante a formação; as abordagens sobre o tema, quando existem, são pontuais e superficiais para proporcionar a aquisição de conhecimentos satisfatórios (Silva et al., 2015).

No Brasil, diferente de outros países, os cursos para formação de profissionais de enfermagem podem ser tanto de nível superior quanto de nível técnico. A categoria de técnicos em enfermagem representa o maior número de postos de trabalho em todas as esferas dos serviços de saúde; atualmente, há mais de 1,3 milhões de técnicos em enfermagem registrados pelos conselhos regionais (COFEN, 2020).

Nesse contexto, o estudante do curso técnico em enfermagem, como futuro profissional, possui um papel diferencial na detecção precoce de uma PCR e realização das manobras de RCP. Entretanto, até o presente momento, há uma escassez de estudos que se propuseram a mensurar o conhecimento destes estudantes sobre SBV para identificação das principais lacunas que envolvem a aplicação do SBV a fim de planejar futuras intervenções para desenvolvimento adequado desta prática. Assim, devido à necessidade de incrementar os estudos nesta população, o objetivo deste estudo foi avaliar o conhecimento de estudantes do curso técnico em enfermagem antes e após treinamento teórico sobre Suporte Básico de Vida envolvendo vítimas adultas.

\section{Metodologia}

Trata-se de um estudo piloto, quase-experimental, com grupo único e avaliação pré e pós-intervenção realizado em uma instituição privada de ensino técnico do sul de Minas Gerais, Brasil. O estudo piloto foi considerado por ter a finalidade de testar as estratégias de intervenção, recrutamento dos participantes, protocolo de intervenção, coleta e análise de dados (Conn et al., 2010).

A população do estudo foi composta por estudantes do curso técnico em enfermagem da instituição selecionada. Por se tratar de um estudo piloto, não há uma fórmula ideal para delimitar o tamanho da amostra (Hertzog, 2008). Assim, os participantes foram selecionados por conveniência a partir dos seguintes critérios de inclusão: estar matriculado no primeiro (I), segundo (II) ou terceiro (III) módulos do curso técnico em enfermagem, ser adulto (idade igual ou superior a 18 anos) e estar presente no dia da coleta de dados. Apenas os estudantes matriculados nestes períodos foram selecionados pelo fato de não terem cursado a disciplina envolvendo urgências e emergências. O critério de exclusão foi: ter cursado isoladamente a disciplina de urgência e emergência. Assim, recrutou-se uma amostra de 74 estudantes.

Para a coleta de dados, foi utilizado um questionário construído e validado de acordo as recomendações da AHA (Diretrizes de 2015, devido ao estudo ter sido realizado em 2019) (AHA, 2015) e conforme recomendações da literatura (Coluci, Alexandre \& Milani, 2015). Os participantes do processo de validação eram enfermeiros, possuíam experiência no atendimento de urgências e emergências há mais de 12 meses, (pré-hospitalares e/ou hospitalares) e eram docentes de cursos da área da saúde. O questionário foi composto por duas seções: I- variáveis sociodemográficas (idade, sexo e anos de escolaridade) e II- variáveis relacionadas ao conhecimento sobre SBV que abrangiam: sinais de possível PCR; condutas iniciais para reconhecimento de uma PCR; número do telefone que deve ser utilizado para pedir ajuda; informações que devem ser fornecidas ao serviço de emergência quando você ligar para pedir ajuda; como se deve posicionar a pessoa que está irresponsiva (inconsciente); número de compressões torácicas aproximadamente que devem ser feitas por minuto quando uma pessoa está em PCR; local de posicionamento das mãos para se realizar as compressões torácicas; sequência de atendimento de uma PCR; sequência correta de uso do desfibrilador externo automático (DEA); procedimento a ser realizado imediatamente após o choque do desfibrilador. 
Assim, a seção II foi composta por 10 questões que continham cinco alternativas a qual o participante deveria selecionar apenas uma resposta.

Após o aceite da instituição participante e aprovação do Comitê de Ética em Pesquisa, os pesquisadores foram ao local de estudo em uma data previamente agendada para realizar o convite aos estudantes, explicar os objetivos do estudo, disponibilizar o Termo de Consentimento Livre e Esclarecido (TCLE) e combinar a data de devolução deste documento assinado e participação no treinamento.

Para evitar viés de coleta, cada uma das três turmas foi abordada no mesmo dia, porém individualmente. Além disso, as questões do questionário de medida de conhecimento sobre SBV foram intercaladas para que cada turma recebesse uma versão diferente a fim de evitar a troca de informações entre elas. Deste modo, os pesquisadores inicialmente aplicaram o questionário de medida do conhecimento sobre SBV e estipularam 20 minutos para retorno com as respostas.

Em seguida, iniciou-se o treinamento teórico propriamente dito. Uma aula composta por informações escritas, figuras e vídeos abordando o conteúdo sobre SBV foi elaborada de acordo o guia internacional da $A H A$ vigente na época (AHA, 2015) e corrigida por dois professores experientes no tema a fim de deixar a aula mais adequada possível. Assim, o treinamento foi ministrado pelo mesmo pesquisador para as três turmas separadamente, com duração aproximada de 60 minutos. Imediatamente após a aula, o questionário sobre SBV novamente foi aplicado com o mesmo tempo de retorno com as respostas.

Os dados coletados foram transferidos para uma planilha do Microsoft Excel 2010®, por meio de dupla digitação. Estatísticas descritivas foram utilizadas para resumir as características sociodemográficas. O teste de Kolmogorov-Smirnov foi utilizado para verificar a distribuição dos dados. Para comparar a mediana do nível de conhecimento e a proporção de acertos antes e após o treinamento, utilizaram-se os testes de Wilcoxon e McNemar, respectivamente. O nível de significância de 5\% foi considerado. Os dados foram analisados usando o software Statistical Package for the Social Sciences (IBM @ SPSS- versão 23.0).

O estudo foi aprovado pelo Comitê de Ética em Pesquisa do Instituto Federal do Sul de Minas - IFSULDEMINAS (CAAE: 20962819.2.0000.8158, parecer $\mathrm{n}^{\circ}$ 3.602.248) e atendeu às exigências éticas previstas pela resolução 466/12 do Conselho Nacional de Saúde do Brasil bem como às recomendações da Declaração de Helsinki.

\section{Resultados}

Dos 74 estudantes que participaram do estudo, 41,9\% ( $\mathrm{n}=31$ ) estavam matriculados no módulo I, 27,0\% ( $\mathrm{n}=20)$ no módulo II e 31,1\% (n=23) no módulo III. A mediana de idade foi de 27,5 anos (min=18; máx=47). Quase a totalidade dos participantes eram mulheres, $(83,8 \% ; n=62)$ com mediana de anos de escolaridade de 14 anos $(\min =9 ;$ máx=17). Em relação à experiência prévia de uma situação de emergência, 52,7\% (n=39), afirmaram já ter presenciado alguma situação.

$\mathrm{Na}$ Tabela 1, são apresentadas a mediana das respostas dos estudantes no pré e pós-teste imediato sobre SBV a uma vítima adulta em PCR. O conhecimento dos estudantes de todos os módulos no pós-teste foi significativamente maior que no pré-teste (medianas 8,0 e 7,0, respectivamente; p<0,001). Na análise isolada de cada um dos módulos, houve aumento significativo do nível de conhecimento nos módulos I e II (p<0,001). 
Tabela 1 - Comparação do nível de conhecimento no pré-teste e pós-teste imediato no curso de Suporte Básico de Vida. Alfenas, MG, 2020.

\begin{tabular}{cccc}
\hline \multirow{2}{*}{ Módulos } & Pré-teste & Pós-teste imediato & \multirow{2}{*}{ p-valor* } \\
\cline { 2 - 3 } & mediana (min-max) & mediana (min-max) & $<$ \\
\hline I, II e III & $7,0(3,0-10,0)$ & $8,0(3,0-10,0)$ & $<\mathbf{0 0 1}$ \\
\hline I & $6,0(3,0-9,0)$ & $8,0(6,0-10,0)$ & $<\mathbf{0 , 0 0 1}$ \\
\hline III & $7,5(5,0-9,0)$ & $9,0(6,0-10,0)$ & 0,064 \\
\hline
\end{tabular}

\footnotetext{
*p-valor obtido por meio do teste de Wilcoxon. Fonte: Autores.
}

Na Tabela 2 são apresentadas as proporções de acertos dos estudantes envolvendo o SBV. Por meio do teste de McNemar, quando comparadas as proporções no pré e pós-teste, observou-se diferença estatisticamente significante na questão 3 (número do telefone que deve ser utilizado para pedir ajuda) ( $\mathrm{p}=0,008)$, questão 5 (posicionamento da vítima irresponsiva) ( $p<0,001$ ), questão 6 (número de compressões torácicas por minuto) ( $p<0,001)$ e questão 7 (local de posicionamento das mãos para se realizar as compressões torácicas) $(\mathrm{p}=0,039)$. Com isso, é possível notar que apenas as questões que envolviam os elos inicias da cadeia de sobrevivência - acionamento do serviço de urgência/emergência e a realização da RCP - apresentaram aumento do número de acertos estatisticamente significante. 
Tabela 2 - Distribuição das respostas corretas dos estudantes antes e após intervenção. Alfenas, MG, 2020.

\begin{tabular}{|c|c|c|c|}
\hline \multirow[t]{2}{*}{ Questões } & Pré-teste & $\begin{array}{l}\text { Pós-teste } \\
\text { imediato }\end{array}$ & \multirow[t]{2}{*}{ p-valor* } \\
\hline & n $(\%)$ & $\mathbf{n}(\%)$ & \\
\hline 1-São sinais de uma possível parada cardiorrespiratória: & $66(89,2)$ & $71(95,9)$ & 0,180 \\
\hline $\begin{array}{l}\text { 2-São condutas iniciais para reconhecimento de uma parada } \\
\text { cardiorrespiratória, exceto: }\end{array}$ & $49(66,2)$ & $49(66,2)$ & 1,000 \\
\hline $\begin{array}{l}\text { 3-Quando você identifica uma situação de emergência, qual é o } \\
\text { número do telefone que deve ser utilizado corretamente para pedir } \\
\text { ajuda? }\end{array}$ & $65(87,8)$ & $73(98,6)$ & $\mathbf{0 , 0 0 8}$ \\
\hline $\begin{array}{l}\text { 4-Quais são as informações que você deve fornecer pelo telefone ao } \\
\text { serviço de emergência quando você ligar para pedir ajuda? }\end{array}$ & $72(97,3)$ & $73(98,6)$ & 1,000 \\
\hline $\begin{array}{l}\text { 5-Como se deve posicionar a pessoa que está irresponsiva } \\
\text { (inconsciente)? }\end{array}$ & $48(64,9)$ & $69(93,2)$ & $<0,001$ \\
\hline $\begin{array}{l}\text { 6- Quando uma pessoa está em parada cardiorrespiratória, quantas } \\
\text { compressões torácicas devem ser realizadas por minuto? }\end{array}$ & $37(50,0)$ & $72(97,3)$ & $<0,001$ \\
\hline $\begin{array}{l}\text { 7-Qual deve ser o local de posicionamento das mãos para se realizar } \\
\text { as compressões torácicas? }\end{array}$ & $63(85,1)$ & $71(95,9)$ & $\mathbf{0 , 0 3 9}$ \\
\hline $\begin{array}{l}\text { 8-Em relação ao atendimento à pessoa em parada cardiorrespiratória, } \\
\text { assinale a sequência correta de atendimento: }\end{array}$ & $25(33,8)$ & $25(33,8)$ & 1,000 \\
\hline $\begin{array}{l}\text { 9-Em relação ao desfibrilador externo automático - DEA, assinale a } \\
\text { alternativa que compreende a sequência correta de sua utilização: }\end{array}$ & $39(52,7)$ & $40(54,1)$ & 1,000 \\
\hline $\begin{array}{l}\text { 10-Imediatamente após o choque do desfibrilador, qual o } \\
\text { procedimento que devemos seguir: }\end{array}$ & $55(74,3)$ & $61(82,4)$ & 0,307 \\
\hline
\end{tabular}

*p-valor obtido por meio do teste de McNemar

Fonte: Autores.

\section{Discussão}

Esse estudo objetivou avaliar o conhecimento de estudantes de um curso técnico em enfermagem antes e após treinamento teórico sobre SBV em adultos. O treinamento teórico para estudantes do curso técnico em enfermagem foi capaz de aumentar a mediana do nível de conhecimento na comparação do pré e pós-teste imediato Segundo Benvenuti et al. (2020), há uma escassez de estudos que avaliam o conhecimento sobre o SBV em estudantes do curso técnico em enfermagem. As evidências científicas encontradas abordaram estudantes de curso superior de enfermagem (Silva et al., 2015; Moraes et al., 2017; Resende et al., 2019; Silva et al., 2020).

O nível de conhecimento após a intervenção foi maior e com significância estatística nos módulos iniciais do curso técnico (primeiro e segundo módulos); algo que não pode ser observado nos estudantes do terceiro módulo. Estudos sobre SBV envolvendo acadêmicos de enfermagem também demostraram uma lacuna no conhecimento ao final da graduação; um maior número de acertos em determinadas questões sobre o protocolo de RCP foi identificado em alunos de períodos menos avançados do curso. Esses resultados destacam a importância da repetição do treinamento tanto teórico quanto prático sobre SBV por meio 
de

metodologias ativas para possibilitar a imersão do estudante na formação desta competência com replicação para a vida profissional (Moraes et al., 2017; Resende et al., 2019; Benvenuti et al., 2020; Carvalho et al., 2020).

No presente estudo, apenas nos itens que compunham os elos inicias das cadeias de sobrevivência preconizados pela AHA (AHA, 2015) pode-se notar diferença estatisticamente significante antes e após o treinamento teórico. Os itens que avaliaram o número de contato utilizado para pedir ajuda, o posicionamento correto de vítimas inconsciente, o número de compressões torácicas que deveriam ser realizadas por minuto bem como o posicionamento das mãos para as compressões torácicas foram os que apresentaram esse aumento significante.

O “número de contato utilizado para pedir ajuda” foi uma variável investigada em um estudo de Benvenuti et al. (2020) que reportou nível satisfatório de conhecimento. Notou-se que essa informação já era de conhecimento dos estudantes antes do treinamento, e intensificou ainda mais após o mesmo. Em situações de emergência, é extremamente importante o conhecimento do telefone do serviço de emergência para que seja acionado imediatamente. Essa atitude do contato rápido deve ser a primeira do algoritmo de SBV a fim de aumentar as chances de sobrevida e reduzir complicações (AHA, 2015). Na questão que investiga o "posicionamento correto de vítimas inconscientes", a resposta predominante foi a de decúbito dorsal horizontal. Este foi um dos itens que mais obteve aumento da pontuação na comparação antes e após o treinamento. Saber corretamente como posicionar a vítima é fundamental para o sucesso do atendimento, pois a realização de compressões torácicas de alta qualidade depende deste posicionamento (AHA, 2020).

Em relação ao número de compressões que deveriam ser realizadas por minuto, observou-se um aumento importante na comparação do pré-teste com o pós-teste. Em um estudo envolvendo a população leiga, mais de $50 \%$ dos participantes erraram as questões relativas às compressões torácicas em geral, demonstrando baixo conhecimento sobre o assunto e a necessidade de treinamento (Dixe \& Gomes, 2015). Entretanto, estudo transversal que avaliou o conhecimento sobre SBV em estudantes dos últimos semestres do curso de graduação em enfermagem, reportou que 81,2\% dos discentes acertaram essa questão (Silva et al., 2015). Deste modo, a chave para a construção do conhecimento sobre SBV está no oferecimento do treinamento seguido de mensuração daquele, como descreve o presente estudo.

Para o "posicionamento das mãos para as compressões torácicas", apesar de sido constatado aumento no número de acertos após o treinamento (95,9\%), mais de $85 \%$ dos participantes já haviam apresentado conhecimento elevado antes da intervenção. Essa ação faz parte do segundo elo da cadeia de sobrevivência, ressaltando a importância das compressões corretas para o retorno da circulação espontânea (AHA, 2015). A compressão torácica exige ênfase não somente na frequência adequada de compressões, mas, também, na minimização de interrupções entre uma manobra e outra durante a RCP. Deste modo, a atuação do futuro profissional da saúde é crucial quando se trata sobre tomada de decisões neste aspecto. Sabe-se que o técnico em enfermagem muitas vezes é o primeiro a avaliar o paciente e iniciar as manobras de RCP, portanto é necessário que esteja qualificado para isso (Benvenuti et al., 2020).

Apesar do aumento de acertos em alguns itens após a aplicação do treinamento teórico, outros, porém, permaneceram com baixo nível de conhecimento, como os itens que investigavam: "condutas iniciais para reconhecimento de uma PCR", "a sequência correta de atendimento" e "o uso do DEA". Quanto as "condutas iniciais para reconhecimento de uma PCR" observouse que não houve alteração do total de acertos antes e após a intervenção (66,2\%), apontando que o conteúdo teórico ministrado não contribuiu com a aprendizagem.

Em relação ao item "sequência correta de atendimento" identificou-se que tanto no pré como no pós-teste o total de acertos foi idêntico, 33,8\%. Para responder esta questão seria preciso que o participante conhecesse as etapas sequenciais de um atendimento de PCR, como: reconhecer o evento, pedir ajuda, iniciar as compressões torácicas e aplicar desfibrilação (quando estivesse disponível no local). Com isso, estas etapas exigiram do participante o raciocínio clínico e conhecimento técnico de 
todo o atendimento. Este fato repetiu-se na investigação do "uso do desfibrilador externo automático", que apesar do número de acertos ter evoluído de 52,7\% para 54,1\%, no pós-teste imediato, é um indicador que aponta a fragilidade de um importante conhecimento dos respondentes deste estudo.

A dificuldade com ações técnicas, como o sequenciamento das ações em uma PCR e de uso do DEA já tem sido apontado por estudos prévios (Dixe \& Gomes, 2015; Carvalho et al., 2020), fazendo-se necessário que outras estratégias de ensino sejam realizadas com a população geral, ajudando nas ações técnicas, uso e manuseio de equipamentos, como o DEA. Apesar dos participantes terem demonstrado conhecimento no número de compressões e posicionamento das mãos, não conseguiram demonstrar conhecimento suficiente nas condutas iniciais, sequência de ações na PCR e uso do DEA, semelhante a estudo com população leiga, sugerindo-se que para ações mais técnicas, intervenções práticas poderiam ajudar no aumento do conhecimento (Miotto et al., 2010; Tony et al., 2020).

Assim, apesar de serem evidentes os benefícios de intervenções que utilizam de diferentes estratégias de ensino, o desenvolvimento de treinamento teórico colaborou para a apreensão de conteúdo, melhorando a capacidade cognitiva dos participantes. Mesmo que a intervenção aplicada não tenha apresentado aumento na quantidade de acertos em todos os itens abordados, o incremento dos números de itens apreendidos na análise dos módulos do curso e em tópicos específicos apontam que a aula teórica foi uma importante estratégia de ensino e aprendizagem, semelhante a outros estudos, que também têm apontado para melhorias no conhecimento apreendido (Miotto et al., 2010; Moraes et al., 2017; Gabriel \& Aluko, 2019; Tony et al., 2020).

Os resultados trazem contribuições no âmbito da enfermagem, saúde, educação, ciência e sociedade. A amostra foi constituída por estudantes que farão parte da classe de maior contingência de corpo de trabalho da saúde, os técnicos em enfermagem, os quais apesar de estarem participando de um curso da área de saúde, são estudantes, leigos e demonstraram conhecimento incipiente para atuação em situações de PCR. Entretanto, na intervenção não foi incluído treinamento prático, o que pode ter dificultado a apreensão de conhecimento. Este fato pode ser justificado por questões de limitação dos laboratórios do local do estudo.

\section{Conclusão}

Os resultados deste treinamento teórico em SBV elevou o nível de conhecimento dos estudantes do curso técnico em enfermagem em informações que não exigiam raciocínio clínico apurado, bem como habilidade técnica, como a correta identificação do número do serviço de saúde, o posicionamento das vítimas, o número de compressões e local de posicionamento das mãos para se realizar as compressões torácicas.

Este achado sugere que outras intervenções, inclusive envolvendo ações de simulação prática, devam ser realizadas a fim de contribuir com o aprendizado de pessoas leigas. Por este ser um dos primeiros estudos a avaliar o conhecimento sobre SBV entre estudantes de curso técnico em enfermagem, sugere-se que novas pesquisas sejam conduzidas, incluindo a comparação de treinamento teórico com prático, simulação, vídeos, jogos educativos e gincanas por exemplo, colaborando para investigação da temática.

\section{Referências}

American Heart Association. (2015). Destaques das Diretrizes da American Heart Association 2015 para RCP e ACE. http://www.bombeiros.ms.gov.br/wpcontent/uploads/2015/10/Atualiza\%C3\%A7\%C3\%A3o-das-Diretrizes-de-RCP-e-ACE-2015.pdf.

American Heart Association (2020). Destaques das Diretrizes de RCP e ACE de 2020 da American Heart Association. https://cpr.heart.org/-/media/cprfiles/cpr-guidelines-files/highlights/hghlghts_2020eccguidelines_portuguese.pdf.

Benvenuti, C., Beccaria, L. M., Barbosa, T. P., Rodrigues, C. D. S., \& Jacon, J. C. (2020). Aprendizagem de estudantes de técnico em enfermagem sobre as manobras de ressuscitação cardiopulmonar em suporte básico de vida. Cuid Enferm., 14, 1, 81-87. 
Bernoche, C., Timerman. S., Polastri, T. F., Giannetti, N. S., Siqueira, A. W. S., Piscopo, A., Sako, Y. K. (2019). Atualização da Diretriz de Ressuscitação Cardiopulmonar e Cuidados Cardiovasculares de Emergência da Sociedade Brasileira de Cardiologia - 2019. Arquivos Brasileiros de Cardiologia, 113, 3, 449663. http://dx.doi.org/10.5935/abc.20190203

Carvalho, L. R., Ferreira, R. B. S., Rios, M. A., Fonseca, E. O. S., \& Guimarães, C. F. (2020). Fatores associados ao conhecimento de pessoas leigas sobre suporte básico de vida. Enfermería Actual de Costa Rica, 38, 163-178. http://dx.doi.org/10.15517/revenf.v0i38.39087.

Conselho Federal de Enfermagem. (2020). Enfermagem em Números. http://www.cofen.gov.br/enfermagem-em-numeros.

Coluci, M. Z. O., Alexandre, N. M. C., \& Milani, D. (2015). Construction of measurement instruments in the area of health. Ciênc. saúde coletiva., 20, 3, 925936. https://doi.org/10.1590/1413-81232015203.04332013.

Conn, V. S., Algase, D. L., Rawl, S. M., Zerwic, J. J., \& Wyman, J. F. (2010). Publishing pilot intervention work. West. J. Nurs. Res., 32, 8, 994-1010. https://doi.org/10.1177/0193945910367229.

Dixe, M. A. C. R., \& Gomes, J. C. R. Conhecimento da população portuguesa sobre Suporte Básico de Vida e disponibilidade para realizar formação. Rev Esc Enferm USP, 49, 4, 640-649. http://10.1590/S0080-623420150000400015.

Gabriel, I. O., \& Aluko, J. O. (2019). Theoretical knowledge and psychomotor skill acquisition of basic life support training programme among secondary school students. World J Emerg Med, 10, 2, 81-87. https://doi.org/10.5847 / wjem.j.1920-8642.2019.02.003

Hertzog, M. A. (2008). Considerations in determining sample size for pilot studies. Res Nurs Health., 31, 2, 180-191. https://doi.org/10.1002/nur.20247.

Matos, D. O. N., Souza, R. S., \& Alves, S. M. (2016). Inclusão da disciplina de primeiros socorros para alunos do ensino básico. R. Interd., 9, 3, 168-78.

Miotto, H. C., Camargos, F. R. S., Ribeiro, C. V., Goulart, E. M. A., \& Moreira, M. C. V. (2010). Efeito na Ressuscitação Cardiopulmonar Utilizando Treinamento Teórico versus Treinamento Teórico-Prático. Arq Bras Cardiol., 95, 3, 328-331. https://doi.org/10.1590/S0066-782X2010005000104.

Moraes, C. L., Vasconcelos, P. R., Sousa, E. A., \& Bellaguarda, M. L. R. (2017). Conhecimento de acadêmicos de enfermagem sobre a reanimação. RECOM, 7, e1779. https://doi.org/10.19175/recom.v7i0.1779

Resende, R. T., Barbosa, A. C. S., Luiz, F. S., Santos, K. B., Frank, D. B. P., Motta, D. S., Tony, A. C. C., \& Carbogim, F. C. (2019). Conhecimento dos acadêmicos de enfermagem sobre suporte básico de vida. J Nurs UFPE, 13, 5, 1231-1236. https://doi.org/10.5205/1981-8963-v13i05a238984p1231-12362019.

Silva, B. K. M., Tassara, K. R., Ansaloni, L. V. S., Moraes, P. H. A., Oliveira, R. A., \& Matias, P. R. S. (2020). O conhecimento acerca do suporte básico de vida: uma revisão integrativa. Braz. J. of Develop., 6, 9, 72021-72039. https://doi.org/10.34117/bjdv6n9-593

Silva, D. V., Jesus, A. P. S., Lima, A. A., Santos, M. A. S., \& Alves, S. L. (2015). Conhecimento de graduandos em enfermagem sobre suporte básico de vida. Revista Baiana de Enfermagem, 29,2,125-34. http://dx.doi.org/10.18471/rbe.v29i2.12648.

Tony, A. C. C., Carbogim, F. C., Motta, D. S., Santos, K. B., Dias, A. A., \& Paiva, A. C. P. C. (2020). Teaching Basic Life Support to schoolchildren: quasiexperimental study. Rev. Latino-Am. Enfermagem, 28, e3340. http://dx.doi.org/10.1590/1518-8345.4078.3340.

World Health Organization. (2017). Cardiovascular diseases (CVDs). https://www.who.int/news-room/fact-sheets/detail/cardiovascular-diseases-(cvds). 